\title{
Cysteines as Redox Molecular Switches and Targets of Disease
}

\author{
Annamaria Fra ${ }^{1 *}$, Edgar D. Yoboue ${ }^{2,3}$ and Roberto Sitia ${ }^{2,3 *}$ \\ ${ }^{1}$ Department of Molecular and Translational Medicine, University of Brescia, Brescia, Italy, ${ }^{2}$ Division of Genetics and Cell \\ Biology, Vita-Salute San Raffaele University, Milan, Italy, ${ }^{3}$ Division of Genetics and Cell Biology, IRCCS San Raffaele Scientific \\ Institute, Milan, Italy
}

Thiol groups can undergo numerous modifications, making cysteine a unique molecular switch. Cysteine plays structural and regulatory roles as part of proteins or glutathione, contributing to maintain redox homeostasis and regulate signaling within and amongst cells. Not surprisingly therefore, cysteines are associated with many hereditary and acquired diseases. Mutations in the primary protein sequence (gain or loss of a cysteine) are most frequent in membrane and secretory proteins, correlating with the key roles of disulfide bonds. On the contrary, in the cytosol and nucleus, aberrant post-translational oxidative modifications of thiol groups, reflecting redox changes in the surrounding environment, are a more frequent cause of dysregulation of protein function. This essay highlights the regulatory functions performed by protein cysteine residues and provides a framework for understanding how mutation and/or (in)activation of this key amino acid can cause disease.

Keywords: cellular redoxstasis, cysteine mutation, signaling pathways, disulfide bonding, protein misfolding

\section{OPEN ACCESS}

Edited by: Angelo Poletti, Università degli Studi di Milano, Italy

Reviewed by: Annalisa Pastore, King's College London, United Kingdom Maria Teresa Carri, University of Rome Tor Vergata, Italy

${ }^{*}$ Correspondence: Annamaria Fra annamaria.fra@unibs.it

Roberto Sitia sitia.roberto@hsr.it

Received: 03 March 2017 Accepted: 15 May 2017 Published: 06 June 2017

Citation:

Fra A, Yoboue ED and Sitia $R$ (2017) Cysteines as Redox Molecular

Switches and Targets of Disease.

Front. Mol. Neurosci. 10:167. doi: 10.3389/fnmol.2017.00167

\section{INTRODUCTION}

Amino acids are much more than mere building blocks of proteins: their different chemical properties dictate the catalytic activity of enzymes, protein half-life and a plethora of different post-translational modifications that govern protein function. This essay concentrates on the role of cysteine, a thiol containing amino acid that can participate in a variety of chemical reactions such as post-translational oxidative modifications. Many of them are reversible at physiological conditions, thereby allowing cysteine to act as a powerful molecular switch, akin to protein phosphorylation-dephosphorylation cycles. Hence, cysteine modifications are not limited to the well-known structural role of disulfide bonds in proteins synthesized in the endoplasmic reticulum (ER), but participate in fundamental intra- and inter-cellular signaling pathways. The downside of the pleiotropic reactivity of cysteines resides is their high susceptibility to undesired activation/inactivation in conditions of redox disequilibrium (either oxidative or reductive stress).

\footnotetext{
Abbreviations: AATD, Alpha-1-antitrypsin deficiency; BiP, Immunoglobulin heavy chain-binding protein; CFTR, Cystic fibrosis transmembrane conductance regulator; CXCR4, C-X-C chemokine receptor type 4; ER, Endoplasmic reticulum; ERAD, ER associated degradation; Ero1, Endoplasmic reticulum oxidoreductin 1; Gpx, Glutathione peroxidase; GR, Glutathione reductase; Grx, Glutaredoxin; GSH/GSSG, Reduced/oxidized glutathione; HMGB1, High mobility group protein B1; KEAP1, Kelch-like ECH-associated protein 1; MD2, Lymphocyte antigen 96; Nrf2, Nuclear factor erythroid 2-related factor 2; PDI, Protein disulfide isomerase; Prx, Peroxiredoxin; PTEN, Phosphatase and tensin homolog; QSOX, Quiescin sulfhydryl oxidase; RAGE/ARGE, Advanced glycosylation end product-specific receptor; ROS, Reactive oxygen species; SOD1, Superoxide Dismutase 1; TLR4, Toll-like receptor 4; TNF, Tumor necrosis factor; TNFR, TNF receptors; Trx, Thioredoxin; TrxR, Thioredoxin reductase; VkOR, Vitamin K epoxide reductase.
} 
In many genetic diseases and cancer, mutations can either directly target a cysteine or affect residues that contribute to maintain optimal cysteine $\mathrm{pKa}$, accessibility and/or reactivity.

Here we briefly discuss redoxstasis in cell compartments and provide examples of disease-associated modifications/mutations of key cysteine residues.

\section{CYSTEINES REACTIVITY AND REDOX HOMEOSTASIS}

Redox reactions involve the gain (reduction) or loss (oxidation) of electrons in the reacting compounds. From its reduced form (SH), the sulfur atom of a cysteine residue can undergo a wide-range of oxidative modifications (Figure 1). Reactivity is greatly enhanced for cysteines whose thiol side chain is in the thiolate form, i.e., deprotonated at physiological $\mathrm{pH}\left(\mathrm{S}^{-}\right)$, and is influenced by structural factors (Ferrer-Sueta et al., 2011). Disulfide bonds stabilize the tertiary and/or quaternary structures of many proteins. They also serve as regulatory functional switches, a prototype being the activation of the bacterial transcription factor OxyR in response to oxidative stress (Zheng et al., 1998; Jo et al., 2015). Progressive cysteine oxidation by $\mathrm{H}_{2} \mathrm{O}_{2}$ leads to cysteine sulfenylation ( $\mathrm{SOH}$ ), sulfinylation $\left(\mathrm{SO}_{2} \mathrm{H}\right)$ and sulfonylation $\left(\mathrm{SO}_{3} \mathrm{H}\right)$. Among these, oxidation to $\mathrm{SO}_{3} \mathrm{H}$ is regarded as irreversible. S-sulfydration (also called persulfidation) can occur after reactions between derivatives of hydrogen sulfide $\left(\mathrm{H}_{2} \mathrm{~S}\right)$ and thiols (Mishanina et al., 2015). Reactive nitrogen species (RNS) like nitric oxide (NO) react with some cysteines causing S-nitrosylation/nitrosation (Evangelista et al., 2013). Cysteines can also undergo lipid modifications including palmitoylation and prenylation or bind metals such as $\mathrm{Zn}, \mathrm{Fe}$ and $\mathrm{Cu}$. This latter property is crucial for formation of zinc fingers and iron-sulfur clusters (Oteiza, 2012; Rouault, 2015). Owing to their nucleophilic properties, thiolate groups also participate in non-redox reactions as in the catalytic groups of cysteine-proteases and ubiquitin ligases. For a detailed discussion on cysteine reactivity, its chemotypes and the methods for their detection, we refer to excellent reviews (Nagy, 2013; Paulsen and Carroll, 2013; Go et al., 2015).

Cysteine thiols are key players in conditions of oxidative stress. Most non-protein antioxidants as well as antioxidant enzymes are thiol based. Glutathione (GSH, $\gamma$-L-Glutamyl-Lcysteinylglycine) acts as a redox buffer and a cofactor of many enzymes including glutathione peroxidases (Gpx) that scavenge peroxides generating oxidized glutathione (GSSG). In humans, there are eight Gpxs, localized in different compartments (Brigelius-Flohé and Maiorino, 2013; Figure 2). Other key peroxide scavengers are peroxiredoxins (Prx; Perkins et al., 2015). Of the six human Prxs, two are localized in mitochondria and one in the ER. Thioredoxins (Trx) and glutaredoxins (Grx) reduce oxidized protein thiols. Oxidized Trx and Grx are reduced by $\operatorname{Trx}$ reductases (TrxR) and GSH, respectively (Holmgren, 1979; Mustacich and Powis, 2000; Fernandes and Holmgren, 2004). Glutathione reductase (GR) is also a key player for redox homeostasis, replenishing the GSH pool at the expense of GSSG.
It is important to stress that both GR and TrxR rely on the NADPH/NADP system for their activity, thus establishing a link between the nicotinamide and thiol redox systems (Jones and Sies, 2015). Another important player is sulfiredoxin-1, an ATP-dependent enzyme capable of reducing sulfinylated proteins (Biteau et al., 2003; Mishra et al., 2015).

\section{REDOX COMPARTMENTALIZATION}

The organelles of eukaryotic cells can differ dramatically with respect to the redox poise of their various redox couples (Figure 2). The chemistry of primordial cells evolved in an oxygen-free atmosphere, and cytosolic and mitochondrial cysteines tend to remain in the reduced states (Go et al., 2015). Incidentally, this is why most cell-free protocols that recapitulate nuclear or cytoplasmic reactions include the addition of DTT or other reductants to work efficiently. In vivo, the establishment of stable disulfide bonds in these compartments is extremely unfavorable because of the combined reducing power of GSH, Grxs and Trxs.

However, there are places where disulfide bonds need to be inserted into selected proteins. For example, the Mia40/Erv1 relay allows formation of disulfide bonds in proteins and their import into the inter-membrane mitochondrial space, where the low Grx pool kinetically favor this process (Mesecke et al., 2005; Kojer et al., 2015; Erdogan and Riemer, 2017).

The redox couples present in organelles of the exocytic pathway display redox poises similar to the extracellular space. In the ER, nascent membrane and secretory proteins form disulfide bonds, preparing for their adult life in the oxidizing extracellular environments. Thus, oxidative power is needed in the ER, but redox conditions must be tightly controlled to allow isomerization or reduction of non-native disulfides. The occurrence of opposite reactions is guaranteed by protein relays capable of selectively inserting or removing disulfides (Fassio and Sitia, 2002; Hagiwara and Nagata, 2012). Oxidative folding is catalyzed by enzymes of the protein disulfide isomerase (PDI) superfamily, which receive oxidative power from oxidases like endoplasmic reticulum oxidoreductin 1 (Ero1) and quiescin sulfhydryl oxidase (QSOX; Bulleid and Ellgaard, 2011; Hudson et al., 2015). The human genome encodes for numerous PDI-like enzymes whose activity largely depends on the number of Trx-like domains and the redox potential of their CXXC motifs (Hatahet and Ruddock, 2009; Okumura et al., 2015). Depending on the surrounding redox and ionic conditions, oxidoreductases may oxidize, isomerize or reduce disulfides. In this wide range of activities, ERdJ5 is most suited for reducing disulfides (Dong et al., 2008; Ushioda et al., 2008). TrxR and import of cytosolic GSH have been proposed as reducing powers to prevent ER hyperoxidation (Molteni et al., 2004; Appenzeller-Herzog, 2011; Poet et al., 2017).

Disulfide interactions with PDI-like enzymes provide key quality control of the secretome, preventing the release of immature proteins. For instance, ERp44, captures proteins with exposed thiols and redox-active enzymes lacking suitable ER localization signals (e.g., Ero1, Prx4, Sumf1), retrieving 


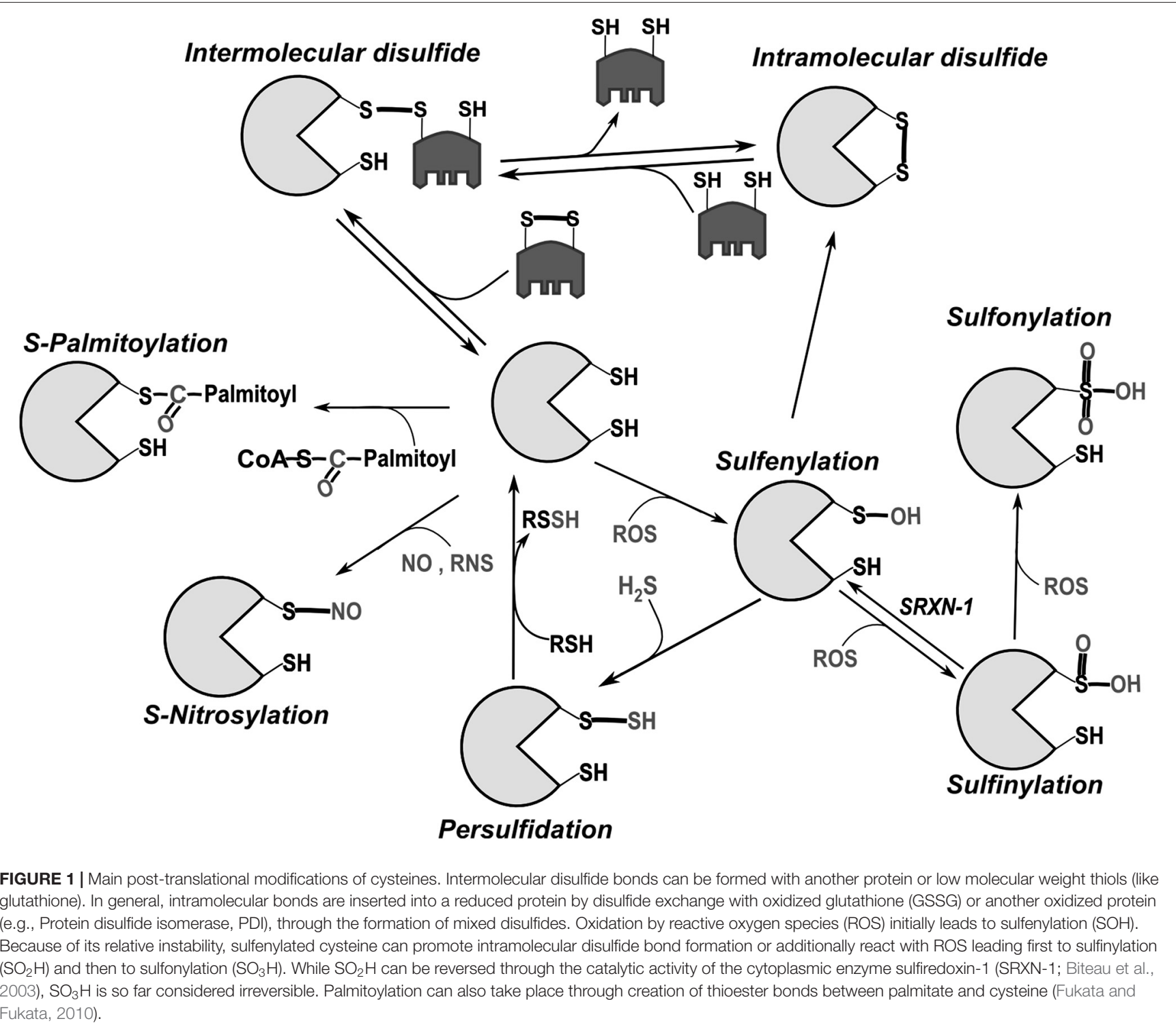

them to the ER (Vavassori et al., 2013; Anelli et al., 2015).

\section{CYSTEINES AS REDOX MOLECULAR SWITCHES}

Mechanisms ensuring tight redoxstasis control are present in the three cellular compartments where protein folding takes place (cytosol, ER and mitochondria) and they are intimately linked to protein quality control (Anelli et al., 2015). However, cells additionally exploit cysteine reactivity for purposes other than oxidative protein folding, namely as switches regulating signaling and adaptive responses.

A prototypic example is provided by the Nuclear factor erythroid 2-related factor 2 (Nrf2), a transcription factor whose nuclear translocation is prevented by interactions with Kelch-like ECH-associating protein 1 (Keap1). Upon oxidation,
Keap1 dissociates from Nrf2, which can reach the nucleus and promote transcription of antioxidant response genes (DinkovaKostova et al., 2002). Recently, unexpected links between Nrf2, redox and ER stress emerged. Irel is a transmembrane protein that initiates the unfolded protein response upon accumulation of misfolded proteins in the ER lumen. Upon oxidative stress, Ire1 is sulfenylated and activates the Nrf2 pathway, abandoning its canonical ER stress sensing function (Hourihan et al., 2016). Thus, a subtle cysteine modification can shift the pathway to which a signal transducer is affiliated.

Redox modifications also play key roles in regulating protein tyrosine phosphorylation. Cysteine oxidative modifications such as $\mathrm{SOH}$, disulfide formation and S-nitrosylation inhibit phosphatase and tensin homolog (PTEN) and other protein tyrosine phosphatases by interfering for example with their cysteine-dependent catalytic activity (Numajiri et al., 2011; Corcoran and Cotter, 2013; Pulido, 2015). As an example 


\section{Extracellular space}

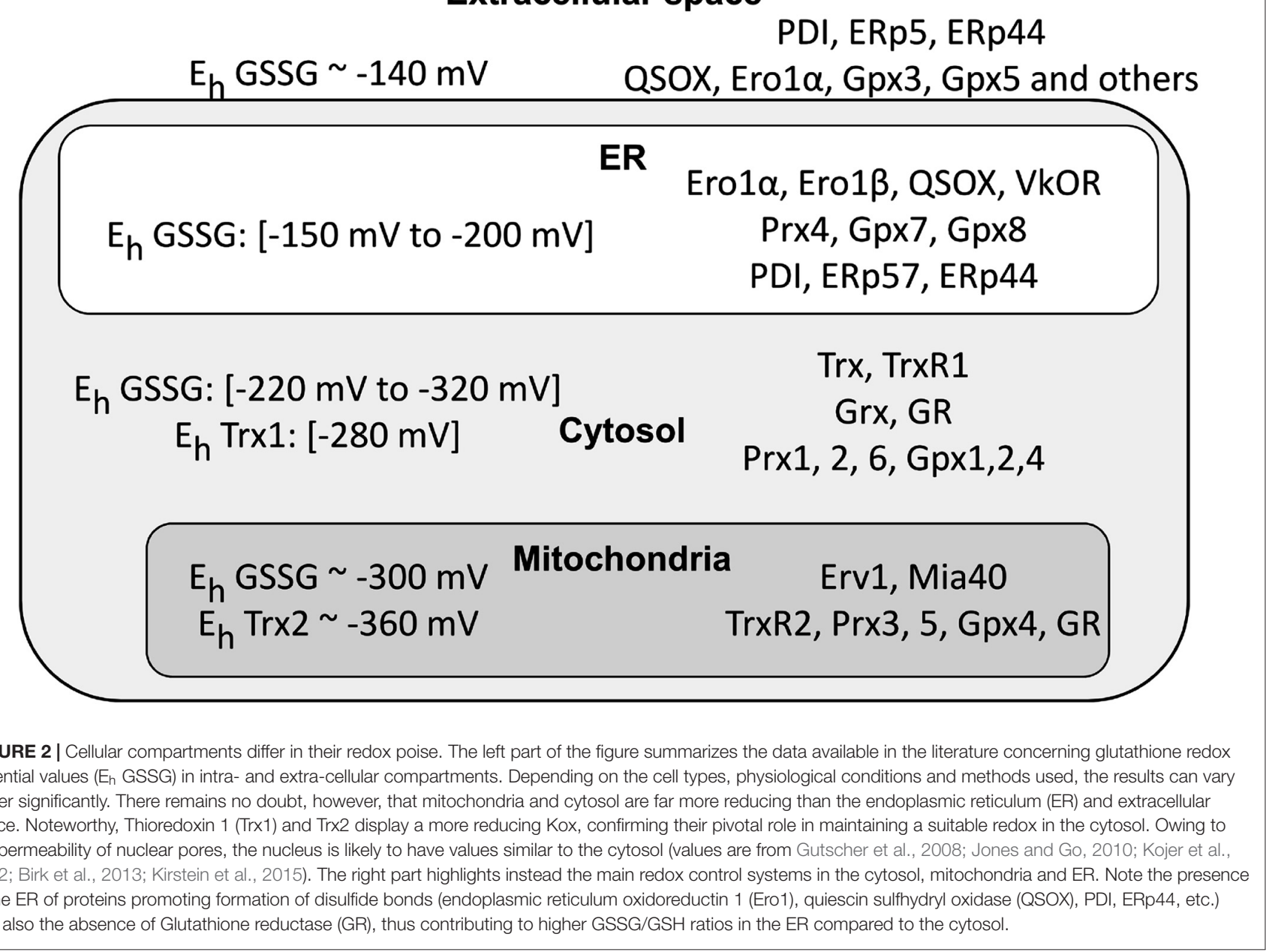

of physiological importance, abolishing this rheostat circuit dampens B lymphocyte activation and antibody production (Bertolotti et al., 2016). Moreover, a growing body of evidence supports the redox regulation of several tyrosine kinases, as described for c-Src (Giannoni and Chiarugi, 2014) and Janus kinase 2 (JAK2; Smith et al., 2012).

High mobility group protein B1 (HMGB1) is a DNA-binding nuclear protein that can be released by stressed cells. In the extracellular space, HMGB1 mediates inflammation or tissue repair, according to its redox state. If fully reduced, it binds to Advanced glycation end product-specific receptor (RAGE) and C-X-C chemokine receptor type 4 (CXCR4) and activates cell migration and autophagy. Upon formation of an intramolecular disulfide bond, HMGB1 binds Toll-like receptor 4 (TLR4)/MD-2 receptors complex and stimulates cytokine secretion. Sulphonylation then inactivates HMGB1, highlighting how a protein switches function depending on its cysteine redox state (Fiuza et al., 2003; Venereau et al., 2012; Vénéreau et al., 2015). Oxidation of a conserved cysteine residue also modulate the permeability of aquaporin 8 by reversibly inhibiting the transport of $\mathrm{H}_{2} \mathrm{O}_{2}$ and $\mathrm{H}_{2} \mathrm{O}$ across the membrane of stressed cells (Medraño-Fernandez et al., 2016).
Another example of redox-based functional re-targeting aimed to prevent protein aggregation is the induction of holdase activity in the ER chaperone Immunoglobulin heavy chainbinding protein (BiP) by cysteine oxidation (Wei et al., 2012; Wang et al., 2014). Similarly, Prx sulphinylation promotes formation of homo-oligomers endowed with chaperone activity (Jang et al., 2004; Hanzén et al., 2016).

Thus, cysteine modifications are key in many intraand inter-cellular signaling and adaptive pathways. The sub-compartmental organization of redoxstasis, based on spatially constrained protein relays (Woo et al., 2010), and the low diffusibility of small redox active compounds such as $\mathrm{H}_{2} \mathrm{O}_{2}$ (Bienert and Chaumont, 2014) can explain how redoxdependent signals can propagate in the presence of powerful antioxidant systems.

\section{CYSTEINES AND DISEASES}

\section{Secretory Proteins}

Owing to the importance of structural and regulatory disulfide bonds in membrane and secretory proteins, mutations in 
luminal cysteines generally have dramatic consequences. Hence, acquisition or loss of a cysteine often causes retention of the mutated protein in the ER by thiol-mediated mechanisms (Anelli et al., 2015), with consequent loss or gain of function. The difficulty in forming the proper array of disulfide bonds in the cysteine-rich domains of many membrane receptors can lead to ER retention and degradation (loss of function), but also gain of function by interchain disulfide bonding that chronically activates signal transduction. An astonishing example comes from type 2A multiple endocrine neoplasia (MEN2A). This severe condition is often due to mutations in the cysteine-rich luminal portion of a tyrosine kinase receptor, RET, with strong genotype-phenotype correlations. The oncogenic hit is the formation of ligand-independent, covalent homodimers that constitutively deliver growth signals (Asai et al., 1995; Mulligan, 2014). RET malfunction can also lead to congenital abnormalities characterized by failure of neuroblast migration and defective maturation of the enteric nervous system (Hirschsprung disease), a condition that in some families coexisted with MEN2A (Takahashi et al., 1999; Frank-Raue et al., 2011).

Many genetic diseases are caused by gain or loss of a cysteine in secretory or membrane proteins. Aberrant thiolmediated interactions via unpaired cysteines can directly provoke ER retention and aggregation besides misfolding. In Pelizaeus-Merzbacher disease, a myelination defect, a subgroup of mutations affecting the extracellular loop of the PLP/DM20 protein impair formation of intramolecular disulfide bridges and cause abnormal protein cross-links, ER retention and oligodendrocyte death (Dhaunchak et al., 2011). Similar mechanisms have been demonstrated in some forms of autism (Comoletti et al., 2004), color blindness (Patel et al., 2005) and von Willebrand disease (Wang et al., 2012).

Mutations of uromodulin, causing medullary cystic kidney disease/familial juvenile hyperuricemic nephropathy most often affect one of the 48 conserved cysteine residues (Rampoldi et al., 2003; Scolari et al., 2015). Cysteine mutations and aberrant disulfide bonding underlie the pathogenesis of CD40 deficiency (Lanzi et al., 2010), TNFR1-associated periodic fever syndrome (Lobito et al., 2006) and MiDY insulin-deficient diabetes (Liu et al., 2010). Mutations causing conformational alterations of alpha-1-antitrypsin make its only cysteine more prone to form aberrant disulfide bonds in the ER, thus facilitating the intracellular retention and polymerization of alpha-1-antitrypsin in Alpha-1-antitrypsin deficiency (AATD; Ronzoni et al., 2016).

Marinesco-Sjogren is a syndrome causing ataxia, intellectual disability and muscle weakness. This rare disease is caused by mutations in Sil1, a cofactor of BiP (Anttonen et al., 2005; Krieger et al., 2013). In yeast recovering from stress, Sill reduces oxidized Kar2, the paralog of human $\mathrm{BiP}$, restoring its normal foldase activity (Siegenthaler et al., 2017). It remains to be seen whether and how mutations in Marinesco-Sjogren patients also impact the reductase function of Sill.

\section{Cytosolic and Nuclear Proteins}

In cytosolic proteins, cysteines can be direct targets of mutations, but more frequently they are dysregulated or inactivated by oxidative stress or other environmental conditions. Both mechanisms have been shown in Parkinson's disease (PD). Parkin (PARK2) is an E3 ubiquitin ligase whose dysfunction causes accumulation of protein aggregates, endangering dopaminergic neurons (Charan and LaVoie, 2015). Parkin is highly expressed in the brain and frequently mutated in autosomal recessive juvenile PD (Biskup et al., 2008). These mutations often affect cysteines, causing loss of function and decreased stability of the enzyme (Wang et al., 2005; Seirafi et al., 2015). Parkin can also be inactivated by S-nitrosylation or sulphonylation (Chung et al., 2004; Meng et al., 2011). Recent studies describe interesting interplays between parkin oxidative modifications, its role in mitochondrial quality control and PD onset (Zhang et al., 2016). In dopaminergic neurodegenerative disorders, a key pathogenetic event is also the inactivation of tyrosine hydroxylase, a rate-limiting enzyme in dopamine and norepinephrine biosynthesis, by oxidative injury (Di Giovanni et al., 2012).

Mutations of the antioxidant superoxide dismutase gene (SOD1) are linked to about one fifth of the cases of familial amyotrophic lateral sclerosis, a degenerative disorder of motor neurons. Wild type SOD1 is a covalent disulfidelinked homodimer localized in part in the mitochondrial intermembrane space. Pathogenic SOD1 mutants form high molecular weight oligomers, inducing mitochondrial dysfunctions (Ferri et al., 2006; Magrané et al., 2009). Noteworthy, intermolecular disulfide cross-links and glutathionylation enhance mutant SOD1 aggregation (Cozzolino et al., 2008; Redler et al., 2011; McAlary et al., 2013), cysteine 111 being a key residue (Valle and Carrì, 2017).

In addition, Alzheimer's disease (AD) is associated with thiol modifications, in particular S-nitrosylation. $\mathrm{NO}$ is produced in the brain by neuronal NO synthase (nNOS) and serves as a key second messenger for instance, regulating neuronal plasticity and survival (Nakamura and Lipton, 2016; Chong et al., 2017). However, aberrant S-nitrosylation of proteins such as PDI and glyceraldehyde-3-phosphate dehydrogenase (GAPDH) can occur in AD (Uehara et al., 2006; Zhao et al., 2015). S-nitrosylation of GAPDH enhances its binding to the ubiquitin ligase Siah1. GAPDH/Siah1 complexes accumulate in the nucleus triggering neuronal apoptosis via excessive protein degradation and trans-nitrosylation signaling cascades (Hara et al., 2005; Sen and Snyder, 2011; Nakamura and Lipton, 2013).

Numerous examples of "gain of cysteine" mutations are found in cancer, p53, KRAS and other oncogenes being preferred targets. The acquired cysteines cause decreased stability or impaired DNA binding of the tumor suppressor p53, while KRAS oncogenes are constitutively activated. Noteworthy, such acquired cysteines are potential targets for antitumor treatments (Visscher et al., 2016).

\section{CONCLUDING REMARKS}

The multiple chemical reactions of cysteines and their reversibility in physiological conditions make them ideal tuneable devices for regulating protein function. Indeed, evolution has increasingly exploited the regulatory potential 
of cysteine chemistry as atmospheric oxygen became more abundant and complex multicellular organisms evolved. The frequency and conservation of this amino acid is indeed higher in mammals ( $>2 \%$ of the proteome) than in prokaryotes $(0.5 \%)$. The examples provided in this essay reveal the pathophysiological relevance of cysteine redox modifications in the different compartments of human cells. Disulfide bonds prevail in the exocytic and endocytic compartments, organelles which are in direct contact with the oxidizing extracellular environment. These covalent bonds increase protein stability, facilitate quality control (Medraño-Fernandez et al., 2014) and underlie the functional regulation of many secreted proteins. A wider range of modifications acts in the cytosol and mitochondria, whose chemistry reflects their origin in an oxygen free atmosphere. Cysteine residues in these compartments are largely found in the reduced thiol/thiolate state, which permits regulation of protein function and activity by way of a wide-range of oxidative post-translational modifications. The redox gradients that form within and amongst cells hence provide ample opportunities to regulate signaling, transcription and other key biological processes. The price we pay is the many diseases caused by cysteine mutations or oxidative deregulation. Novel reagents (Chen et al., 2013; Kim et al., 2015; Bilan and Belousov, 2016; Wagener et al., 2016) are being

\section{REFERENCES}

Anelli, T., Sannino, S., and Sitia, R. (2015). Proteostasis and "redoxtasis" in the secretory pathway: tales of tails from ERp44 and immunoglobulins. Free Radic. Biol. Med. 83, 323-330. doi: 10.1016/j.freeradbiomed.2015.02.020

Anttonen, A.-K., Mahjneh, I., Hämäläinen, R. H., Lagier-Tourenne, C., Kopra, O., Waris, L., et al. (2005). The gene disrupted in Marinesco-Sjögren syndrome encodes SIL1, an HSPA5 cochaperone. Nat. Genet. 37, 1309-1311. doi: $10.1038 / \mathrm{ng} 1677$

Appenzeller-Herzog, C. (2011). Glutathione- and non-glutathione-based oxidant control in the endoplasmic reticulum. J. Cell Sci. 124, 847-855. doi: 10.1242/jcs. 080895

Asai, N., Iwashita, T., Matsuyama, M., and Takahashi, M. (1995). Mechanism of activation of the ret proto-oncogene by multiple endocrine neoplasia $2 \mathrm{~A}$ mutations. Mol. Cell. Biol. 15, 1613-1619. doi: 10.1128/MCB.15.3.1613

Bertolotti, M., Farinelli, G., Galli, M., Aiuti, A., and Sitia, R. (2016). AQP8 transports NOX2-generated $\mathrm{H} 2 \mathrm{O} 2$ across the plasma membrane to promote signaling in B cells. J. Leukoc. Biol. 100, 1071-1079. doi: 10.1189/jlb. 2ab0116-045r

Bienert, G. P., and Chaumont, F. (2014). Aquaporin-facilitated transmembrane diffusion of hydrogen peroxide. Biochim. Biophys. Acta 1840, 1596-1604. doi: 10.1016/j.bbagen.2013.09.017

Bilan, D. S., and Belousov, V. V. (2016). New tools for redox biology: from imaging to manipulation. Free Radic. Biol. Med. doi: 10.1016/j.freeradbiomed.2016.12. 004 [Epub ahead of print].

Birk, J., Meyer, M., Aller, I., Hansen, H. G., Odermatt, A., Dick, T. P., et al. (2013). Endoplasmic reticulum: reduced and oxidized glutathione revisited. J. Cell Sci. 126, 1604-1617. doi: 10.1242/jcs.117218

Biskup, S., Gerlach, M., Kupsch, A., Reichmann, H., Riederer, P., Vieregge, P., et al. (2008). Genes associated with Parkinson syndrome. J. Neurol. 255, 8-17. doi: 10.1007/s00415-008-5005-2

Biteau, B., Labarre, J., and Toledano, M. B. (2003). ATP-dependent reduction of cysteine-sulphinic acid by S. cerevisiae sulphiredoxin. Nature 425, 980-984. doi: 10.1038/nature02075

Brigelius-Flohé, R., and Maiorino, M. (2013). Glutathione peroxidases. Biochim. Biophys. Acta 1830, 3289-3303. doi: 10.1016/j.bbagen.2012.11.020 developed to better understand cysteine modifications and their links with disease, ultimately offering ample practical exploitations (Nakamura and Lipton, 2016; Wani and Murray, 2017).

\section{AUTHOR CONTRIBUTIONS}

AF, EDY and RS discussed the concepts and pitfalls, and wrote the manuscript.

\section{ACKNOWLEDGMENTS}

The authors thank Dr. Mattia Laffranchi (University of Brescia, Italy), Dr. Luca Rampoldi (San Raffaele Scientific Institute, Milan, Italy), Dr. Bruce Morgan (University of Kaiserslautern, Germany) and the members of their labs for stimulating discussions. AF thanks Fondazione Cariplo (2013-0967), EDY (PCOFUND-GA-2010-267264 INVEST), RS AIRC (IG14559), Fondazione Banca del Monte di Lombardia Fondazione Cariplo (2015-0591), Ministero della Salute (PE-2011-02352286) and Telethon (GGP15059) for generous support. We apologize to the many colleagues whose fundamental work could not be cited for space constraints.

Bulleid, N. J., and Ellgaard, L. (2011). Multiple ways to make disulfides. Trends Biochem. Sci. 36, 485-492. doi: 10.1016/j.tibs.2011.05.004

Charan, R. A., and LaVoie, M. J. (2015). Pathologic and therapeutic implications for the cell biology of parkin. Mol. Cell. Neurosci. 66, 62-71. doi: 10.1016/j.mcn. 2015.02.008

Chen, Y.-J., Ching, W.-C., Lin, Y.-P., and Chen, Y.-J. (2013). Methods for detection and characterization of protein S-nitrosylation. Methods 62, 138-150. doi: 10.1016/j.ymeth.2013.04.016

Chong, C.-M., Ai, N., Ke, M., Tan, Y., Huang, Z., Li, Y., et al. (2017). Roles of nitric oxide synthase isoforms in neurogenesis. Mol. Neurobiol. doi: 10.1007/s12035017-0513-7 [Epub ahead of print].

Chung, K. K. K., Thomas, B., Li, X., Pletnikova, O., Troncoso, J. C., Marsh, L., et al. (2004). S-Nitrosylation of Parkin regulates ubiquitination and compromises Parkin's protective function. Science 304, 1328-1331. doi: 10.1126/science. 1093891

Comoletti, D., De Jaco, A., Jennings, L. L., Flynn, R. E., Gaietta, G., Tsigelny, I., et al. (2004). The Arg451Cys-neuroligin-3 mutation associated with autism reveals a defect in protein processing. J. Neurosci. 24, 4889-4893. doi: 10.1523/jneurosci.0468-04.2004

Corcoran, A., and Cotter, T. G. (2013). Redox regulation of protein kinases. FEBS J. 280, 1944-1965. doi: 10.1111/febs. 12224

Cozzolino, M., Amori, I., Pesaresi, M. G., Ferri, A., Nencini, M., and Carrì, M. T. (2008). Cysteine 111 affects aggregation and cytotoxicity of mutant $\mathrm{Cu}, \mathrm{Zn}$ superoxide dismutase associated with familial amyotrophic lateral sclerosis. J. Biol. Chem. 283, 866-874. doi: 10.1074/jbc.m705657200

Dhaunchak, A. S., Colman, D. R., and Nave, K.-A. (2011). Misalignment of PLP/DM20 transmembrane domains determines protein misfolding in Pelizaeus-Merzbacher disease. J. Neurosci. 31, 14961-14971. doi: 10.1523/JNEUROSCI.2097-11.2011

Di Giovanni, G., Pessia, M., and Di Maio, R. (2012). Redox sensitivity of tyrosine hydroxylase activity and expression in dopaminergic dysfunction. CNS Neurol. Disord. Drug Targets 11, 419-429. doi: 10.2174/1871527128007 92938

Dinkova-Kostova, A. T., Holtzclaw, W. D., Cole, R. N., Itoh, K., Wakabayashi, N., Katoh, Y., et al. (2002). Direct evidence that sulfhydryl groups of Keapl are the sensors regulating induction of phase 2 enzymes that protect against 
carcinogens and oxidants. Proc. Natl. Acad. Sci. U S A 99, 11908-11913. doi: 10.1073/pnas.172398899

Dong, M., Bridges, J. P., Apsley, K., Xu, Y., and Weaver, T. E. (2008). ERdj4 and ERdj5 are required for endoplasmic reticulum-associated protein degradation of misfolded surfactant protein C. Mol. Biol. Cell 19, 2620-2630. doi: 10.1091/mbc.E07-07-0674

Erdogan, A. J., and Riemer, J. (2017). Mitochondrial disulfide relay and its substrates: mechanisms in health and disease. Cell Tissue Res. 367, 59-72. doi: 10.1007/s00441-016-2481-z

Evangelista, A. M., Kohr, M. J., and Murphy, E. (2013). S-Nitrosylation: specificity, occupancy and interaction with other post-translational modifications. Antioxid. Redox Signal. 19, 1209-1219. doi: 10.1089/ars.20 12.5056

Fassio, A., and Sitia, R. (2002). Formation, isomerisation and reduction of disulphide bonds during protein quality control in the endoplasmic reticulum. Histochem. Cell Biol. 117, 151-157. doi: 10.1007/s00418-001 $-0364-0$

Fernandes, A. P., and Holmgren, A. (2004). Glutaredoxins: glutathionedependent redox enzymes with functions far beyond a simple thioredoxin backup system. Antioxid. Redox Signal. 6, 63-74. doi: 10.1089/1523086047719 78354

Ferrer-Sueta, G., Manta, B., Botti, H., Radi, R., Trujillo, M., and Denicola, A. (2011). Factors affecting protein thiol reactivity and specificity in peroxide reduction. Chem. Res. Toxicol. 24, 434-450. doi: 10.1021/tx10 0413v

Ferri, A., Cozzolino, M., Crosio, C., Nencini, M., Casciati, A., Gralla, E. B., et al. (2006). Familial ALS-superoxide dismutases associate with mitochondria and shift their redox potentials. Proc. Natl. Acad. Sci. U S A 103, 13860-13865. doi: 10.1073/pnas.0605814103

Fiuza, C., Bustin, M., Talwar, S., Tropea, M., Gerstenberger, E., Shelhamer, J. H., et al. (2003). Inflammation-promoting activity of HMGB1 on human microvascular endothelial cells. Blood 101, 2652-2660. doi: 10.1182/blood2002-05-1300

Frank-Raue, K., Rybicki, L. A., Erlic, Z., Schweizer, H., Winter, A., Milos, I., et al. (2011). Risk profiles and penetrance estimations in multiple endocrine neoplasia type $2 \mathrm{~A}$ caused by germline RET mutations located in exon 10. Hum. Mutat. 32, 51-58. doi: 10.1002/humu.21385

Fukata, Y., and Fukata, M. (2010). Protein palmitoylation in neuronal development and synaptic plasticity. Nat. Rev. Neurosci. 11, 161-175. doi: $10.1038 / \mathrm{nrn} 2788$

Giannoni, E., and Chiarugi, P. (2014). Redox circuitries driving Src regulation. Antioxid. Redox Signal. 20, 2011-2025. doi: 10.1089/ars.2013.5525

Go, Y.-M., Chandler, J. D., and Jones, D. P. (2015). The cysteine proteome. Free Radic. Biol. Med. 84, 227-245. doi: 10.1016/j.freeradbiomed.2015. 03.022

Gutscher, M., Pauleau, A.-L., Marty, L., Brach, T., Wabnitz, G. H., Samstag, Y., et al. (2008). Real-time imaging of the intracellular glutathione redox potential. Nat. Methods 5, 553-559. doi: 10.1038/nmeth.1212

Hagiwara, M., and Nagata, K. (2012). Redox-dependent protein quality control in the endoplasmic reticulum: folding to degradation. Antioxid. Redox Signal. 16, 1119-1128. doi: 10.1089/ars.2011.4495

Hanzén, S., Vielfort, K., Yang, J., Roger, F., Andersson, V., Zamarbide-Forés, S., et al. (2016). Lifespan control by redox-dependent recruitment of chaperones to misfolded proteins. Cell 166, 140-151. doi: 10.1016/j.cell.2016.05.006

Hara, M. R., Agrawal, N., Kim, S. F., Cascio, M. B., Fujimuro, M., Ozeki, Y., et al. (2005). S-nitrosylated GAPDH initiates apoptotic cell death by nuclear translocation following Siah1 binding. Nat. Cell Biol. 7, 665-674. doi: $10.1038 /$ ncb1268

Hatahet, F., and Ruddock, L. W. (2009). Protein disulfide isomerase: a critical evaluation of its function in disulfide bond formation. Antioxid. Redox Signal. 11, 2807-2850. doi: 10.1089/ARS.2009.2466

Holmgren, A. (1979). Glutathione-dependent synthesis of deoxyribonucleotides. Characterization of the enzymatic mechanism of Escherichia coli glutaredoxin. J. Biol. Chem. 254, 3672-3678.

Hourihan, J. M., Moronetti Mazzeo, L. E., Fernández-Cárdenas, L. P., and Blackwell, T. K. (2016). Cysteine sulfenylation directs IRE-1 to activate the SKN-1/Nrf2 antioxidant response. Mol. Cell 63, 553-566. doi: 10.1016/j.molcel. 2016.07.019
Hudson, D. A., Gannon, S. A., and Thorpe, C. (2015). Oxidative protein folding: from thiol-disulfide exchange reactions to the redox poise of the endoplasmic reticulum. Free Radic. Biol. Med. 80, 171-182. doi: 10.1016/j.freeradbiomed. 2014.07.037

Jang, H. H., Lee, K. O., Chi, Y. H., Jung, B. G., Park, S. K., Park, J. H., et al. (2004). Two enzymes in one; two yeast peroxiredoxins display oxidative stressdependent switching from a peroxidase to a molecular chaperone function. Cell 117, 625-635. doi: 10.1016/j.cell.2004.05.002

Jo, I., Chung, I.-Y., Bae, H.-W., Kim, J.-S., Song, S., Cho, Y.-H., et al. (2015). Structural details of the OxyR peroxide-sensing mechanism. Proc. Natl. Acad. Sci. US A 112, 6443-6448. doi: 10.1073/pnas.1424495112

Jones, D. P., and Go, Y.-M. (2010). Redox compartmentalization and cellular stress. Diabetes Obes. Metab. 12, 116-125. doi: 10.1111/j.1463-1326.2010. 01266.x

Jones, D. P., and Sies, H. (2015). The redox code. Antioxid. Redox Signal. 23, 734-746. doi: 10.1089/ars.2015.6247

Kim, H.-J., Ha, S., Lee, H. Y., and Lee, K.-J. (2015). ROSics: chemistry and proteomics of cysteine modifications in redox biology. Mass Spectrom. Rev. 34, 184-208. doi: 10.1002/mas.21430

Kirstein, J., Morito, D., Kakihana, T., Sugihara, M., Minnen, A., Hipp, M. S., et al. (2015). Proteotoxic stress and ageing triggers the loss of redox homeostasis across cellular compartments. EMBO J. 34, 2334-2349. doi: 10.15252/embj. 201591711

Kojer, K., Bien, M., Gangel, H., Morgan, B., Dick, T. P., and Riemer, J. (2012). Glutathione redox potential in the mitochondrial intermembrane space is linked to the cytosol and impacts the Mia40 redox state. EMBO J. 31, 3169-3182. doi: 10.1038/emboj.2012.165

Kojer, K., Peleh, V., Calabrese, G., Herrmann, J. M., and Riemer, J. (2015). Kinetic control by limiting glutaredoxin amounts enables thiol oxidation in the reducing mitochondrial intermembrane space. Mol. Biol. Cell 26, 195-204. doi: 10.1091/mbc.E14-10-1422

Krieger, M., Roos, A., Stendel, C., Claeys, K. G., Sonmez, F. M., Baudis, M., et al. (2013). SIL1 mutations and clinical spectrum in patients with Marinesco-Sjogren syndrome. Brain 136, 3634-3644. doi: 10.1093/brain/ awt 283

Lanzi, G., Ferrari, S., Vihinen, M., Caraffi, S., Kutukculer, N., Schiaffonati, L., et al. (2010). Different molecular behavior of CD40 mutants causing hyper-IgM syndrome. Blood 116, 5867-5874. doi: 10.1182/blood-2010-03-2 74241

Liu, M., Haataja, L., Wright, J., Wickramasinghe, N. P., Hua, Q.-X., Phillips, N. F., et al. (2010). Mutant INS-gene induced diabetes of youth: proinsulin cysteine residues impose dominant-negative inhibition on wild-type proinsulin transport. PLoS One 5:e13333. doi: 10.1371/journal.pone. 0013333

Lobito, A. A., Kimberley, F. C., Muppidi, J. R., Komarow, H., Jackson, A. J., Hull, K. M., et al. (2006). Abnormal disulfide-linked oligomerization results in ER retention and altered signaling by TNFR1 mutants in TNFR1-associated periodic fever syndrome (TRAPS). Blood 108, 1320-1327. doi: 10.1182/blood2005-11-006783

Magrané, J., Hervias, I., Henning, M. S., Damiano, M., Kawamata, H., and Manfredi, G. (2009). Mutant SOD1 in neuronal mitochondria causes toxicity and mitochondrial dynamics abnormalities. Hum. Mol. Genet. 18, 4552-4564. doi: 10.1093/hmg/ddp421

McAlary, L., Yerbury, J. J., and Aquilina, J. A. (2013). Glutathionylation potentiates benign superoxide dismutase 1 variants to the toxic forms associated with amyotrophic lateral sclerosis. Sci. Rep. 3:3275. doi: 10.1038/srep03275

Medraño-Fernandez, I., Bestetti, S., Bertolotti, M., Bienert, G. P., Bottino, C., Laforenza, U., et al. (2016). Stress regulates aquaporin-8 permeability to impact cell growth and survival. Antioxid. Redox Signal. 24, 1031-1044. doi: 10.1089/ars.2016.6636

Medraño-Fernandez, I., Fagioli, C., Mezghrani, A., Otsu, M., and Sitia, R. (2014). Different redox sensitivity of endoplasmic reticulum associated degradation clients suggests a novel role for disulphide bonds in secretory proteins. Biochem. Cell Biol. 92, 113-118. doi: 10.1139/bcb-2013-0090

Meng, F., Yao, D., Shi, Y., Kabakoff, J., Wu, W., Reicher, J., et al. (2011). Oxidation of the cysteine-rich regions of parkin perturbs its E3 ligase activity and contributes to protein aggregation. Mol. Neurodegener. 6:34. doi: 10.1186/17501326-6-34 
Mesecke, N., Terziyska, N., Kozany, C., Baumann, F., Neupert, W., Hell, K., et al. (2005). A disulfide relay system in the intermembrane space of mitochondria that mediates protein import. Cell 121, 1059-1069. doi: 10.1016/j.cell.2005. 04.011

Mishanina, T. V., Libiad, M., and Banerjee, R. (2015). Biogenesis of reactive sulfur species for signaling by hydrogen sulfide oxidation pathways. Nat. Chem. Biol. 11, 457-464. doi: 10.1038/nchembio. 1834

Mishra, M., Jiang, H., Wu, L., Chawsheen, H. A., and Wei, Q. (2015). The sulfiredoxin-peroxiredoxin (Srx-Prx) axis in cell signal transduction and cancer development. Cancer Lett. 366, 150-159. doi: 10.1016/j.canlet.2015. 07.002

Molteni, S. N., Fassio, A., Ciriolo, M. R., Filomeni, G., Pasqualetto, E., Fagioli, C., et al. (2004). Glutathione limits Ero1-dependent oxidation in the endoplasmic reticulum. J. Biol. Chem. 279, 32667-32673. doi: 10.1074/jbc. M404992200

Mulligan, L. M. (2014). RET revisited: expanding the oncogenic portfolio. Nat. Rev. Cancer 14, 173-186. doi: 10.1038/nrc3680

Mustacich, D., and Powis, G. (2000). Thioredoxin reductase. Biochem. J. 346, 1-8. doi: 10.1042/0264-6021:3460001

Nagy, P. (2013). Kinetics and mechanisms of thiol-disulfide exchange covering direct substitution and thiol oxidation-mediated pathways. Antioxid. Redox Signal. 18, 1623-1641. doi: 10.1089/ars.2012.4973

Nakamura, T., and Lipton, S. A. (2013). Emerging role of protein-protein transnitrosylation in cell signaling pathways. Antioxid. Redox Signal. 18, 239-249. doi: 10.1089/ars.2012.4703

Nakamura, T., and Lipton, S. A. (2016). Protein S-Nitrosylation as a therapeutic target for neurodegenerative diseases. Trends Pharmacol. Sci. 37, 73-84. doi: 10.1016/j.tips.2015.10.002

Numajiri, N., Takasawa, K., Nishiya, T., Tanaka, H., Ohno, K., Hayakawa, W., et al. (2011). On-off system for PI3-kinase-Akt signaling through S-nitrosylation of phosphatase with sequence homology to tensin (PTEN). Proc. Natl. Acad. Sci. U S A 108, 10349-10354. doi: 10.1073/pnas.1103503108

Okumura, M., Kadokura, H., and Inaba, K. (2015). Structures and functions of protein disulfide isomerase family members involved in proteostasis in the endoplasmic reticulum. Free Radic. Biol. Med. 83, 314-322. doi: 10.1016/j. freeradbiomed.2015.02.010

Oteiza, P. I. (2012). Zinc and the modulation of redox homeostasis. Free Radic. Biol. Med. 53, 1748-1759. doi: 10.1016/j.freeradbiomed.2012.08.568

Patel, K. A., Bartoli, K. M., Fandino, R. A., Ngatchou, A. N., Woch, G., Carey, J., et al. (2005). Transmembrane S1 mutations in CNGA3 from achromatopsia 2 patients cause loss of function and impaired cellular trafficking of the cone CNG channel. Invest. Ophthalmol. Vis. Sci. 46, 2282-2290. doi: 10.1167/iovs. 05-0179

Paulsen, C. E., and Carroll, K. S. (2013). Cysteine-mediated redox signaling: chemistry, biology and tools for discovery. Chem. Rev. 113, 4633-4679. doi: $10.1021 / \mathrm{cr} 300163 \mathrm{e}$

Perkins, A., Nelson, K. J., Parsonage, D., Poole, L. B., and Karplus, P. A. (2015). Peroxiredoxins: guardians against oxidative stress and modulators of peroxide signaling. Trends Biochem. Sci. 40, 435-445. doi: 10.1016/j.tibs.2015. 05.001

Poet, G. J., Oka, O. B., van Lith, M., Cao, Z., Robinson, P. J., Pringle, M. A., et al. (2017). Cytosolic thioredoxin reductase 1 is required for correct disulfide formation in the ER. EMBO J. 36, 693-702. doi: 10.15252/embj. 201695336

Pulido, R. (2015). PTEN: a yin-yang master regulator protein in health and disease. Methods 77-78, 3-10. doi: 10.1016/j.ymeth.2015.02.009

Rampoldi, L., Caridi, G., Santon, D., Boaretto, F., Bernascone, I., Lamorte, G., et al. (2003). Allelism of MCKD, FJHN and GCKD caused by impairment of uromodulin export dynamics. Hum. Mol. Genet. 12, 3369-3384. doi: $10.1093 / \mathrm{hmg} / \mathrm{ddg} 353$

Redler, R. L., Wilcox, K. C., Proctor, E. A., Fee, L., Caplow, M., and Dokholyan, N. V. (2011). Glutathionylation at Cys-111 induces dissociation of wild type and FALS mutant SOD1 dimers. Biochemistry 50, 7057-7066. doi: 10.1021/bi200614y

Ronzoni, R., Berardelli, R., Medicina, D., Sitia, R., Gooptu, B., and Fra, A. M. (2016). Aberrant disulphide bonding contributes to the ER retention of alphal-antitrypsin deficiency variants. Hum. Mol. Genet. 25, 642-650. doi: $10.1093 / \mathrm{hmg} / \mathrm{ddv} 501$
Rouault, T. A. (2015). Mammalian iron-sulphur proteins: novel insights into biogenesis and function. Nat. Rev. Mol. Cell Biol. 16, 45-55. doi: 10.1038/nrm3909

Scolari, F., Izzi, C., and Ghiggeri, G. M. (2015). Uromodulin: from monogenic to multifactorial diseases. Nephrol. Dial. Transplant. 30, 1250-1256. doi: 10.1093/ndt/gfu300

Seirafi, M., Kozlov, G., and Gehring, K. (2015). Parkin structure and function. FEBS J. 282, 2076-2088. doi: 10.1111/febs.13249

Sen, N., and Snyder, S. H. (2011). Neurotrophin-mediated degradation of histone methyltransferase by $S$-nitrosylation cascade regulates neuronal differentiation. Proc. Natl. Acad. Sci. U S A 108, 20178-20183. doi: 10.1073/pnas.11178 20108

Siegenthaler, K. D., Pareja, K. A., Wang, J., and Sevier, C. S. (2017). An unexpected role for the yeast nucleotide exchange factor Sill as a reductant acting on the molecular chaperone BiP. Elife 6:e24141. doi: 10.7554/eLife.24141

Smith, J. K., Patil, C. N., Patlolla, S., Gunter, B. W., Booz, G. W., and Duhé, R. J. (2012). Identification of a redox-sensitive switch within the JAK2 catalytic domain. Free Radic. Biol. Med. 52, 1101-1110. doi: 10.1016/j.freeradbiomed. 2011.12.025

Takahashi, M., Iwashita, T., Santoro, M., Lyonnet, S., Lenoir, G. M., and Billaud, M. (1999). Co-segregation of MEN2 and Hirschsprung's disease: the same mutation of RET with both gain and loss-of-function? Hum. Mutat. 13, 331-336. doi: 10.1002/(SICI)1098-1004(1999)13:4331::AID-HUMU11 >3. $0 . \mathrm{CO} ; 2-\#$

Uehara, T., Nakamura, T., Yao, D., Shi, Z.-Q., Gu, Z., Ma, Y., et al. (2006). $S$-nitrosylated protein-disulphide isomerase links protein misfolding to neurodegeneration. Nature 441, 513-517. doi: 10.1038/nature 04782

Ushioda, R., Hoseki, J., Araki, K., Jansen, G., Thomas, D. Y., and Nagata, K. (2008). ERdj5 is required as a disulfide reductase for degradation of misfolded proteins in the ER. Science 321, 569-572. doi: 10.1126/science. 1159293

Valle, C., and Carrì, M. T. (2017). Cysteine modifications in the pathogenesis of ALS. Front. Mol. Neurosci. 10:5. doi: 10.3389/fnmol.2017.00005

Vavassori, S., Cortini, M., Masui, S., Sannino, S., Anelli, T., Caserta, I. R., et al. (2013). A pH-regulated quality control cycle for surveillance of secretory protein assembly. Mol. Cell 50, 783-792. doi: 10.1016/j.molcel.2013.04.016

Venereau, E., Casalgrandi, M., Schiraldi, M., Antoine, D. J., Cattaneo, A., De Marchis, F., et al. (2012). Mutually exclusive redox forms of HMGB1 promote cell recruitment or proinflammatory cytokine release. J. Exp. Med. 209, 1519-1528. doi: 10.1084/jem.20120189

Vénéreau, E., Ceriotti, C., and Bianchi, M. E. (2015). DAMPs from cell death to new life. Front. Immunol. 6:422. doi: 10.3389/fimmu.2015.00422

Visscher, M., Arkin, M. R., and Dansen, T. B. (2016). Covalent targeting of acquired cysteines in cancer. Curr. Opin. Chem. Biol. 30, 61-67. doi: 10.1016/j. cbpa.2015.11.004

Wagener, K. C., Kolbrink, B., Dietrich, K., Kizina, K. M., Terwitte, L. S., Kempkes, B., et al. (2016). Redox indicator mice stably expressing genetically encoded neuronal roGFP: versatile tools to decipher subcellular redox dynamics in neuropathophysiology. Antioxid. Redox Signal. 25, 41-58. doi: 10.1089 /ars.2015.6587

Wang, J.-W., Groeneveld, D. J., Cosemans, G., Dirven, R. J., Valentijn, K. M., Voorberg, J., et al. (2012). Biogenesis of Weibel-Palade bodies in von Willebrand's disease variants with impaired von Willebrand factor intrachain or interchain disulfide bond formation. Haematologica 97, 859-866. doi: 10.3324/haematol.2011.057216

Wang, J., Pareja, K. A., Kaiser, C. A., and Sevier, C. S. (2014). Redox signaling via the molecular chaperone $\mathrm{BiP}$ protects cells against endoplasmic reticulumderived oxidative stress. Elife 3:e03496. doi: 10.7554/eLife.03496

Wang, C., Tan, J. M. M., Ho, M. W. L., Zaiden, N., Wong, S. H., Chew, C. L. C., et al. (2005). Alterations in the solubility and intracellular localization of parkin by several familial Parkinson's disease-linked point mutations. J. Neurochem. 93, 422-431. doi: 10.1111/j.1471-4159.2005.03023.x

Wani, R., and Murray, B. W. (2017). Analysis of cysteine redox post-translational modifications in cell biology and drug pharmacology. Methods Mol. Biol. 1558, 191-212. doi: 10.1007/978-1-4939-6783-4_9

Wei, P.-C., Hsieh, Y.-H., Su, M.-I., Jiang, X., Hsu, P.-H., Lo, W.-T., et al. (2012). Loss of the oxidative stress sensor NPGPx compromises GRP78 chaperone 
activity and induces systemic disease. Mol. Cell 48, 747-759. doi: 10.1016/j. molcel.2012.10.007

Woo, H. A., Yim, S. H., Shin, D. H., Kang, D., Yu, D.-Y., and Rhee, S. G. (2010). Inactivation of peroxiredoxin I by phosphorylation allows localized $\mathrm{H}_{2} \mathrm{O}_{2}$ accumulation for cell signaling. Cell 140, 517-528. doi: 10.1016/j.cell.2010. 01.009

Zhang, Z., Liu, L., Jiang, X., Zhai, S., and Xing, D. (2016). The essential role of Drp1 and its regulation by S-nitrosylation of parkin in dopaminergic neurodegeneration: implications for Parkinson's disease. Antioxid. Redox Signal. 25, 609-622. doi: 10.1089/ars.2016.6634

Zhao, Q.-F., Yu, J.-T., and Tan, L. (2015). S-Nitrosylation in Alzheimer's disease. Mol. Neurobiol. 51, 268-280. doi: 10.1007/s12035-014$8672-2$
Zheng, M., Aslund, F., and Storz, G. (1998). Activation of the OxyR transcription factor by reversible disulfide bond formation. Science 279, 1718-1721. doi: $10.1126 /$ science. 279.5357 .1718

Conflict of Interest Statement: The authors declare that the research was conducted in the absence of any commercial or financial relationships that could be construed as a potential conflict of interest.

Copyright $\odot 2017$ Fra, Yoboue and Sitia. This is an open-access article distributed under the terms of the Creative Commons Attribution License (CC BY). The use, distribution or reproduction in other forums is permitted, provided the original author(s) or licensor are credited and that the original publication in this journal is cited, in accordance with accepted academic practice. No use, distribution or reproduction is permitted which does not comply with these terms. 